\title{
Mucinous Cystadenocarcinoma of the Colon during Pregnancy
}

\author{
T. Shoji ${ }^{a} \quad$ N. Sakurai ${ }^{b} \quad$ K. Misumi ${ }^{a} \quad$ I. Matsuda ${ }^{a} \quad$ T. Teradac \\ Departments of aSurgery, b'Gynecology and cPathology, Shizuoka Municipal \\ Shimizu Hospital, Shizuoka City, Japan
}

\section{Key Words}

Mucinous cystadenocarcinoma · Colon · Pregnancy

\begin{abstract}
A rare case of mucinous adenocarcinoma of the cecum in a pregnant woman is described. A 32-year-old Korean woman was diagnosed as having an abdominal tumor immediately after giving birth. Abdominal computed tomography demonstrated a smooth mass measuring $10 \mathrm{~cm}$ in diameter on the right side of the abdomen. Acute abdomen developed 3 days after birth. At emergency surgery, volvulus of a polypoid tumor was detected at the cecum apart from the normal appendix. We successfully performed a tumorectomy; however, histopathological examination demonstrated mucinous adenocarcinoma with a massive blood clot.
\end{abstract}

\section{Introduction}

Primary mucinous cystadenocarcinoma occurring in the colon is rare, moreover almost all such tumors occur at the appendix [1]. Mucinous cystadenocarcinoma of the intestinal tract is extremely rare. A polypoid lesion of mucinous cystadenocarcinoma has not previously been reported. Moreover, our case is extremely rare because volvulus of a polypoid tumor occurred in association with pregnancy.

\section{Case Report}

A 32-year-old Korean woman was admitted to the Shizuoka Municipal Shimizu Hospital in August 2007 to give birth. Three days after the birth, the patient suddenly developed acute epigastric pain. Board-like rigidity with rebound tenderness was noted in the epigastrium, and abdominal computed tomography (CT) demonstrated a $10 \mathrm{~cm}$ mass on the uterus (fig. 1). Laboratory studies demonstrated a white blood cell count of $9,400 / \mathrm{mm}^{3}$, carcinoembryonic antigen level (CEA) of $40.7 \mathrm{ng} / \mathrm{ml}$ and carbohydrate antigen 19-9 (CA19-9) of 24,116 U/ml (table 1). We thus diagnosed a volvulus of the tumor originating from the uterus. An emergency laparotomy was performed immediately, and a giant volvulus tumor originating from the cecum wall was identified (fig. 2). The tumor was rotated about $540^{\circ}$. We resected the tumor and a normal appendix and uterus were confirmed. Macroscopically, the resected specimen showed an encapsulated, cystic tumor measuring $10 \mathrm{~cm}$ in diameter with a smooth 
surface that was connected to the cecum wall with a stalk (fig. 3 ). The sections showed a blood clot. At the top of the tumor, atypical tubular structures with clear cytoplasm were seen only focally (ig. 4 ). $\mathrm{Ki}-67$ labeling was high. The features are compatible with mucinous cystadenocarcinoma.

Immunohistochemical analysis showed CEA expression. Colonoscopy demonstrated negative findings up to the terminal ileum. The postoperative course was uneventful and the patient was followed by the outpatient department. Complete remission was achieved and no sign of recurrence has been observed in the 15 months after surgery.

\section{Discussion}

Mucinous cystadenocarcinomas demonstrate high-grade cellular dysplasia and frequently invade the stroma beyond the muscularis mucosa [2]. Mucoceles of the colon are uncommon $[1,3]$. Almost all such tumors occur at the appendix $[2,4-6]$. To our knowledge, this is the first report of mucinous cystadenocarcinoma on the cecum wall during pregnancy.

Tumor marker levels during pregnancy are not significant [7]. Elevated CEA shows a high correlation with tumor recurrence and the presence of metastasis from colorectal cancer [8]. Chuang et al. [6] reported that the CEA level is elevated in mucinous cystadenocarcinoma. They suggested regular follow-up of the serum CEA level for the early detection of tumor recurrence. In our case, the serum CEA level was slightly elevated, but the serum CA19-9 level was extremely high. Postoperatively CEA and CA19-9 levels normalized.

The clinical symptomatology of mucocele of appendicitis patients is not specific. Abdominal pain is present in $64 \%$ of patients and a palpable ileocecal mass is found in $50 \%$ of cases [4]. Our patient demonstrated sudden onset of right lower quadrant abdominal pain three days after delivery. Pressure or release by the uterus might have led to volvulus of the tumor.

Sonography usually shows a cystic encapsulated lesion with liquid content $[4,5,7]$. CT scan shows a low-density, encapsulated, thin-walled mass that is not enhanced by contrast medium $[2-6,9]$. Previously reported magnetic resonance imaging showed the same pattern as CT [7]. In our case, an encapsulated $10 \mathrm{~cm}$ diameter mass was located over the uterus on CT.

Mucinous peritoneal tumors tend to be associated with a poor prognosis, despite extensive treatment, including radical surgical excision and adjuvant intraperitoneal and systemic chemotherapy. The 10 -year survival of patients with mucinous cystadenocarcinomas is $65 \%$ among patients treated with hemicolectomy and only $37 \%$ among patients who undergo appendectomy alone [5]. In our case, the malignant lesion was distant from the wall of the cecum and mesenterium. From this perspective, the patient selected adjuvant chemotherapy after sufficient explanation and informed consent.

In conclusion, we report a patient with volvulus of a cecal tumor after giving birth. 
Case Reports in | Case Rep Gastroenterol 2009;3:43-48 Gastruenterology

Table 1. Laboratory data

\begin{tabular}{llll}
\hline WBC & $9,400 \mu \mathrm{l}$ & $\mathrm{Na}$ & $137 \mathrm{nmol} / \mathrm{l}$ \\
$\mathrm{RBC}$ & $239 \times 10^{4} / \mu \mathrm{l}$ & $\mathrm{K}$ & $4.2 \mathrm{nmol} / \mathrm{l}$ \\
$\mathrm{Hb}$ & $7.8 \mathrm{~g} / \mathrm{dl}$ & $\mathrm{Cl}$ & $101 \mathrm{nmol} / \mathrm{l}$ \\
$\mathrm{Plt}$ & $26.0 \times 10^{4} / \mu \mathrm{l}$ & $\mathrm{CRP}$ & $8.8 \mathrm{mg} / \mathrm{dl}$ \\
$\mathrm{TP}$ & $4.7 \mathrm{~g} / \mathrm{dl}$ & $\mathrm{CEA}$ & $40.7 \mathrm{ng} / \mathrm{ml}$ \\
$\mathrm{Alb}$ & $2.5 \mathrm{~g} / \mathrm{dl}$ & $\mathrm{CA} 19-9$ & $24,116 \mathrm{U} / \mathrm{ml}$ \\
$\mathrm{GOT}$ & $10 \mathrm{IU} / \mathrm{CA} 125$ & $707.8 \mathrm{U} / \mathrm{ml}$ \\
$\mathrm{GPT}$ & $6 \mathrm{IU} / \mathrm{CA} 72-4$ & $88.2 \mathrm{U} / \mathrm{ml}$ \\
$\mathrm{BUN}$ & $11 \mathrm{mg} / \mathrm{dl}$ & $\mathrm{SCC}$ & $<0.5 \mathrm{ng} / \mathrm{ml}$ \\
$\mathrm{Cre}$ & $0.5 \mathrm{mg} / \mathrm{dl}$ & & \\
\hline
\end{tabular}

Fig. 1. Abdominal CT demonstrated a low-density, encapsulated, thin-walled mass.

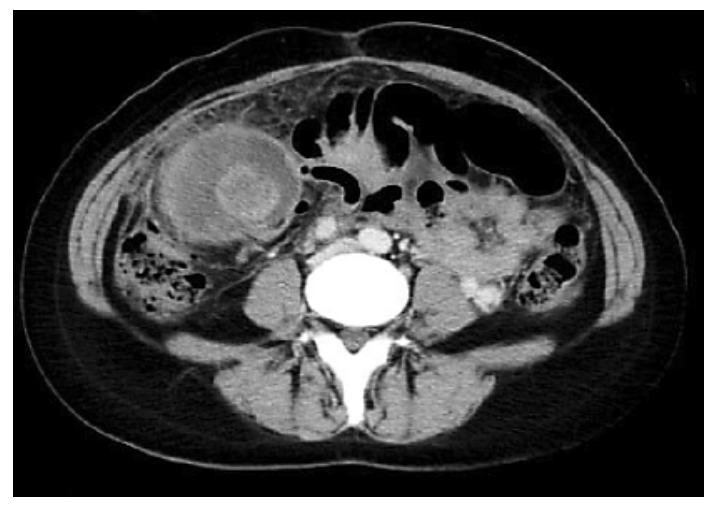




\begin{tabular}{r|l|l|l} 
Case Reports $/$ G & $\begin{array}{l}\text { Case Rep Gastroenterol 2009;3:43-48 } \\
\text { Dol: 10.1159/000210437 }\end{array}$ & Published online: April 10, 2009 & $\begin{array}{l}\text { O 2009 S. Karger AG, Basel } \\
\text { ISSN 1662-0631 } \\
\text { www.karger.com/crg }\end{array}$ \\
\hline
\end{tabular}

Fig. 2. a Giant volvulus tumor originating from the cecal wall. b After resection of the tumor. c Schematic representation of $\mathbf{b}$. The tumor stalk was away from the appendix and uterus. $\mathbf{a}=$ Appendix, $\mathrm{u}=$ uterus, $\mathrm{c}=$ cecum, $\mathrm{t}=$ tumor stalk.
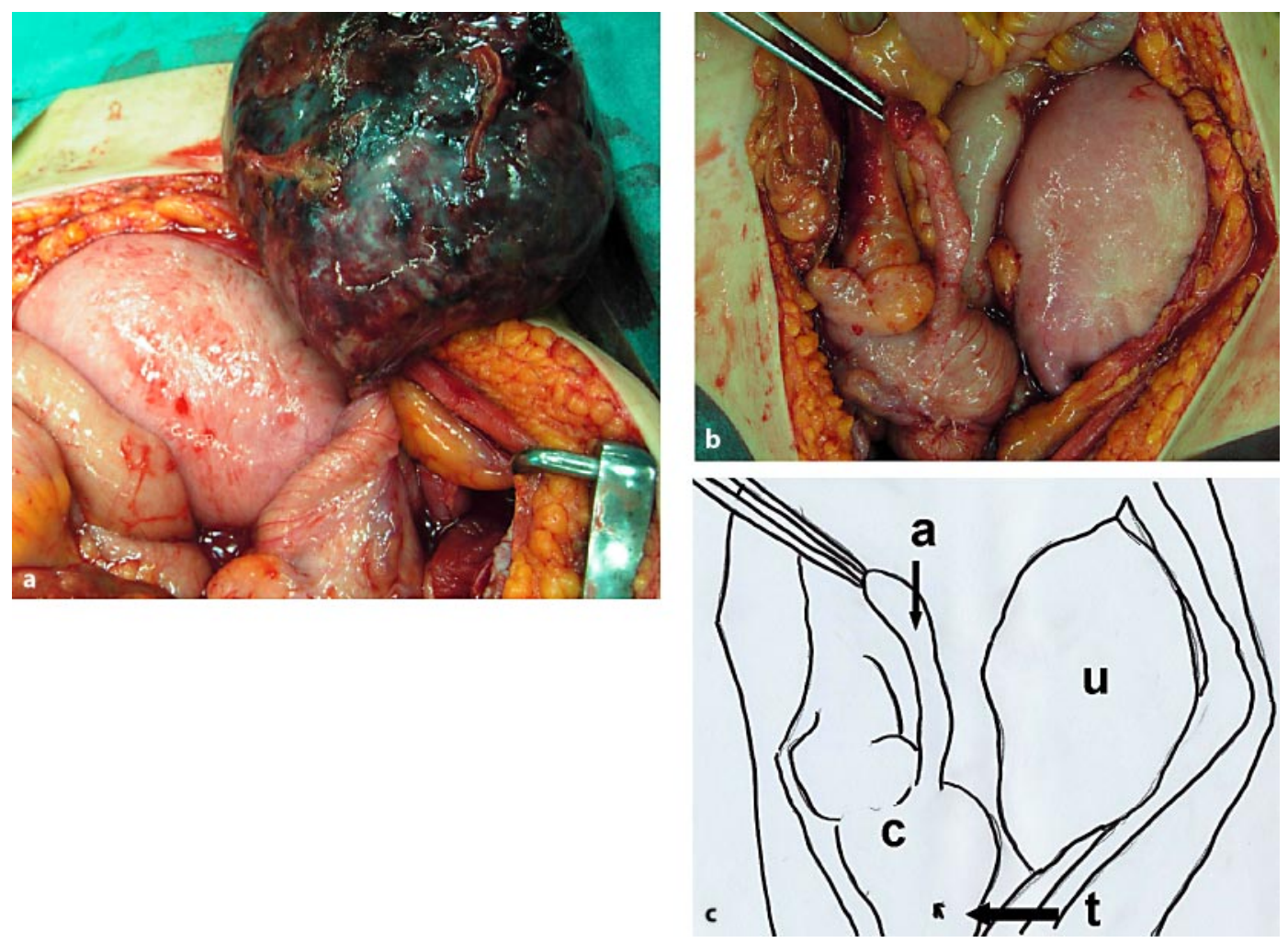

Fig. 3. Resected specimen showing the encapsulated cystic mass.

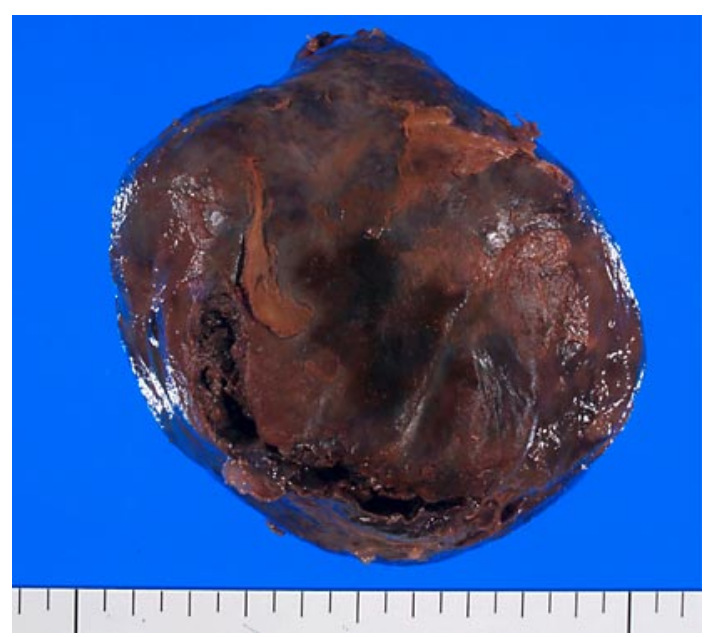




\begin{tabular}{r|l|l|l} 
Case Reports $h$ Ch & $\begin{array}{l}\text { Case Rep Gastroenterol 2009;3:43-48 } \\
\text { Dol: } 10.1159 / 000210437\end{array}$ & Published online: April 10, 2009 & $\begin{array}{l}\text { I 2009 S. Karger AG, Basel } \\
\text { ISSN 1662-0631 } \\
\text { www.karger.com/crg }\end{array}$ \\
\hline
\end{tabular}

Fig. 4. Histological examination demonstrated that the tumor was a mucinous cystadenocarcinoma $(\mathrm{H} \& \mathrm{E}, \times 100)$.

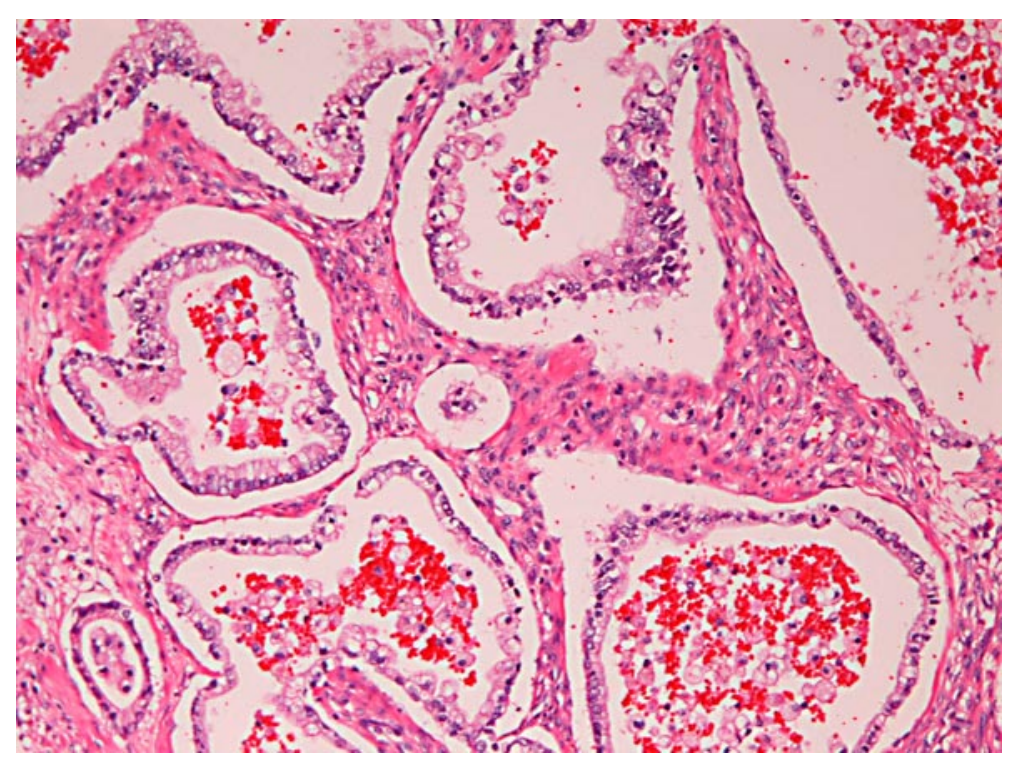




\section{References}

1 Nakayama H, Akikusa B, Kondo Y, Saito N, Sarashina H, Okui K: Mucinous cystadenocarcinoma of the colon. Report of a Case. Dis Colon Rectum 1989;32:243-246.

-2 Miyakura $\mathrm{Y}$, Iwai $\mathrm{H}$, Togashi $\mathrm{K}$, et al: Mucinous cystadenocarcinoma of the appendix invading the ascending colon with fistula formation: report of a case. Surg Today 2007;37:806-810.

-3 Adachi S, Doy M, Shimizu HT, Ozaki A: A small mucinous cystadenocarcinoma of the liver detected by a fluid-fluid level on ultrasonography. Surg Today 1996;26:439-441.

4 Srdjan PD, Milan MS, Nada VK, et al: Mucinous cystadenoma of the appendix associated with adenocarcinoma of the sigmoid colon and hepatocellular carcinoma of the liver: report of a case. World J Gastroenterol 2006;12:1975-1977.

5 Sato H, Fujisaki M, Takahashi T, et al: Mucinous cystadenocarcinoma in the appendix in a patient with nonrotation: report of a case. Surg Today 2001;31:1012-1015.

6 Chuang MT, Liaw WS, Wang WY, et al: Psoas abscess due to mucinous cystadenocarcinoma of the appendix: a case report. Chin Med J 1995;55:412-416.

7 Ishioka S, Hayashi T, Endo T, et al: Advanced epithelial ovarian carcinoma during pregnancy. Int J Clin Oncol 2007;12:375-378.

8 Yamashita K, Aitio ML, Dawson JR: Characterization of the carcinoembryonic antigen activity associated with cyst fluids of mucinous ovarian cystadenocarcinoma. Cancer Res 1979;39:1760-1765.

-9 Kessler TM, Kessler W, Neuweiler J, Nachbur BH: Treatment of a case of primary retroperitoneal mucinous cystadenocarcinoma: Is adjuvant hysterectomy and bilateral salpingo-oophorectomy justified? Am J Obstet Gynecol 2002;187:227232. 